\title{
"A Possibly Sick Bird that Could Inform Broader Public Policy": Discourse Analysis of Humor and News Discourse in "Last Week Tonight with John Oliver"
}

\author{
Baudelio Muro Samano \\ University of Guanajuato, MEXICO \\ Division of Social Sciences and Humanities
}

Received: 10 June 2021 • Accepted: 30 July 2021 • Published Online: 14 October 2021

Abstract

Comedy news has become a relevant and influential referent of news media diet for people in the U.S. One of the major exponents of this kind of outlets in the U.S. is the show Last Week Tonight. This paper analyzes the objective value of comedy discourse and news discourse from this show and aims at investigating its persuasive effect on people. Van Dijk's (1983) model of news discourse analysis, and Attardo's (2010), and Attardo and Raskin (1991) sequences of joke organization and General Theory of Verbal Humor joke-forming resources were used to apply a conceptual framework for the jokes and the news piece structure of this paper. Results showed that humor is used in pieces of information as de-escalation to the seriousness of news discourse, and that this show has a robust news discourse structure similar to serious news programs.

Keywords: comedy news discourse, canned jokes, news discourse analysis, "Last Week Tonight", discourse analysis.

\section{Introduction}

Comedy shows are unique news media outlets that have gained popularity in recent times. The approach these kinds of shows provide to news broadcasting and media consumption has become quite relevant for today's society, and their approach should be seen with nuance and objective criticism (Burns, 2020), due to the power of laughter used in the communicative process. Comedy, as Attardo states (2010), fulfills social functions. The ones connected to comedy news are mediation and social management. As a result, humorous content can be used as a transitional device that permits the presentation of situations, themes, or events that can engage interaction, but also as a tool to ease interactions such as communicating news and/or raising awareness of current real-life events.

Last Week Tonight (LWT) is a show produced by actor and comedian John Oliver, with a group of other comedy writers, journalists, and researchers. It was created in 2014, and it is currently broadcasted by the channel Home Box Office (HBO), and it has a YouTube channel where its main news piece investigations are uploaded for public consumption online.

To analyze this show's unique take on comedy news, I suggest a composed conceptual discourse analysis framework, which analyzes the jokes used in a news piece segment of the show available on YouTube and the general structure of the news piece in question. This paper analyzes

(C) Authors. Terms and conditions of Creative Commons Attribution 4.0 International (CC BY 4.0) apply. Correspondence: Baudelio Muro Samano, University of Guanajuato, Division of Social Sciences and Humanities, Guanajuato, MEXICO. E-mail: baudelio.muro@outlook.com. 
both the news piece structure and the jokes used in such piece from the show to demonstrate the value in discourse analysis that comedy news holds in the portrayal of this novel kind of news format. The news discourse analysis was carried out implementing Van Dijk's (1983) approach to news discourse to understand how the news piece's news coverage process occurs and is structured. For the jokes' analysis, the conceptual framework is a combination of both Attardo's (2010) and Attardo and Raskin's (1991) sequential organization of canned jokes and the General Theory Verbal Humor joke-forming resources, as well as Long and Graesser's (1988) descriptors from their taxonomy of jokes.

- Comedy news are outlets that have become influential in the U.S. society as part of many people's media diet (Burns, 2020).

- Last Week Tonight is one of the most recognizable comedy news outlets that focuses on delivering current-news with a comedic twist.

- This paper analyzes comedy and news' discourse objectively in order to understand the concrete value comedy news have as both humor and news discourse.

- A conceptual framework brought together from Van Dijk's (1983) model of news discourse analysis, Attardo's (2010), and Attardo and Raskin (1991) sequences of joke organization and General Theory of Verbal Humor joke-forming resources was used to applies a conceptual framework for the jokes and the news piece structure of this paper.

- The results obtained proved that the news discourse management of a LWT's news piece had the same robust structure than a news piece or article found in any news program or in a newspaper.

- It was also found that the jokes are used to alleviate tension and/or harshness on the pieces of information given to the audience.

\subsection{Humor discourse analysis}

Understanding the linguistic value humor is challenging. Long and Graesser (1988) explain that humor is a complex linguistic phenomenon, even challenged and discussed in the realm of psychology. They state that humor, "like all speech acts, must be decoded and comprehended in the context of rules of language, rules of conversation, the speaker's intentions, and other dimensions of the social situation" (p. 35). Long and Graesser (1988) then define humor as anything said or done in purpose or inadvertently that can be considered funny or amazing to others. When in a conversation, for example, certain expectations are met with playful word plays or incongruous reactions, among other ways to interpret and decode humor from social interactions.

Overall, defining humor concretely can be difficult since people could interpret sarcasm, irony, and even ridiculous situations as humor. Humor, for Attardo (2002), is seen as "an umbrella term encompassing programmatically all the semantic field of humor and humorous forms" (p. 160). For irony and sarcasm to be considered humorous, Attardo (2002) comments, there should be an element of playfulness in the utterance, hence it would be understood as funny. Attardo further comments that there is a distinction between humor competence and performance in the process of identifying humor in conversational interactions. Humor competence is defined as "the capacity of a speaker to process semantically a given text and to locate a set of relationships among its components, such that he/she would identify the text (or part of it) as humorous in an ideal situation" (Attardo, 2002: 161). Humor performance, then, is defined as "the actual encounter of two speakers, in a given actual place and time (from which) speaker A says something and speaker B processes the text (what A said) and, having recognized the humor, reacts by laughing" (Ibid.). Attardo (2002) further comments that for humor performance to happen, 
speaker A and B may not need to be present physically, thus providing to the conceptual framework of analysis the validity needed when applied to comedy shows, comedy specials, prerecorded jokes, among other humorous texts.

Attardo (2002) offers an explanation of humor in both semantic and pragmatic views. Semantically speaking, he comments that humor is understood as the opposition of two scripts or frames that can be compatible in their entirety or partially within a text. This means that, with the concept of the "incongruity-resolution model" from Long and Graesser (1988), humor occurs when "an incongruous punch line is resolved to a preceding text" (p. 58). Incongruity provides the punch-line (or premise) perceived with a sense of surprise from the hearer, and the preceding text could generate a humorous reaction, in most cases. This can be up to debate, and Long and Graesser (1998) do go on it, but for the sake of the linguistic background for this project, we will use such an example to establish the semantic view of humor. Regarding humor's pragmatic view, Attardo comments that it is understood "as a violation of Grice's Cooperative Principle" (p. 162), which explains that both parts within a conversation are cooperating with each other to engage in seeking meaning from their utterances. Attardo further comments on this view that

humor is a real violation, not a flout or a mentioned violation... [that] differs from other modes of communication that involve violations of the Cooperative Principle, such as lying, in that its purpose (amusement) is largely approved of socially and that significant amounts of humor are incorporated in everyday conversations, exchanges, etc. (Attardo, 2002: 162).

Such definition helps to establish what Attardo (2010) later referred to as a key characteristic of humor: its social functions. He comments that there are primary and secondary social functions. The former is defined as the effects "that the speaker may [wish to] achieve directly by using humorous segments or texts in his/her discourse" (p. 323). Four main classes of primary social functions of humor in communicative processes illustrate Attardo's characteristics (2010: 323-329):

(1) Social management: humor is used as a tool to facilitate in-group interaction and strengthen in-group bonding or out-group rejection;

(2) Decommitment: humorous communication is retractable, i.e., the speaker may back off from his/her utterance without loss of face;

(3) Mediation: humorous discourse is a "transitional device" that allows the introduction of topics or situations with the sense of embarrassing or aggressive interaction;

(4) Defunctionalization: humor not used for transmission of information (its principal function), but for playful (ludic) purposes.

Secondary social functions are defined as the effects "that are achieved either indirectly or without the knowledge or intent of the user" (Attardo, 2010: 323). The classes of secondary social functions of humor in communicative processes are far less extensive than in the primary classes, yet they are also worth mentioning for this research project. The three functions mentioned by Attardo (2010) are to provide real-life information, taboo information, and to reveal information from the speaker to the hearer, as in setting the mood for humor in the conversation, acceptance of the subject matter for the conversation, among other elements described as "metafunctions".

\subsection{News pieces discourse analysis}

After establishing a rather general framework of how humor works in discourse analysis, I will explain how news discourse is then laid out and understood. Van Dijk (1983) 
mentions discourse types when referring to news discourse, saying that there is "specialization in certain discourse types or genres, such as everyday conversation, stories, classroom discourse, textbooks, proverbs, or news" (p. 25). He further adds that discourse types should be then characterized and situated within the "terms of a specific combination of various textual and contextual properties” (Van Dijk, 1983: 25).

From the previous argument, he then specifies three general characteristics for news discourse. The first one is described as functionality, which entails how surface structures of discourse and meanings from it can be developed and analyzed either "indications about characteristics of the speaker (e.g., intentions, wishes, moods), the relations between speaker and hearer (e.g., confidence, intimacy, power), and the type of social situation (e.g., a court trial, a school lesson, a birthday party)" (Van Dijk, 1983: 25). That means that within a social context, the properties of discourse can then be understood as functional related to their social contexts, such as the cases of the examples given above.

The second characteristic Van Dijk (1983) comments related to news discourse is meaningfulness. This one explains how a textual sequence should hold meaning, in comparison with just a collection of sentences. For that meaning to occur, local and global coherence should foster unity within each other. The former terms, local and global coherence, are understood as to how meaningfully related clauses and sentences are within a text (local) and how larger parts of the discourse, the theme or topic of it, can be considered coherent: that if we refer to a section of or the whole discourse discussing something "real" (global). The real explained by Van Dijk as "facts and to components of facts, such as objects, persons, properties, actions, or events" (pp. 2526).

The last characteristic Van Dijk provides news discourse with is goal-directedness. This characteristic encases how communicative situations are considered in uttering meaningful discourses, thus defining such situations as speech acts. Van Dijk (1983) provides an example of these characteristics functioning to provide further understanding: "if we want to invite someone to a party, we may first want to know (by asking questions) whether the other person is free that night" (Van Dijk, 1983: 26). He further comments that, from the example given in the last sentence, meaningful discourse is said with the intention of performing a social act, understood also as a speech act. Van Dijk (1983) adds that "such an act is not performed in a vacuum, but has a reason, some concrete purpose" (p. 26).

Van Dijk states that these characteristics are present in each discourse type, in the sense that "each discourse type has its social functions, associated with different possible surface structures (style), different meanings and ways of establishing coherence, and different speech acts" (1983: 26). Van Dijk adds that discourse can contain different other elements that can contribute to its established goals, such as rhetorical operations such as rhymes, metaphors, sayings, and even jokes if one takes Attardo's (2010) structure for jokes into consideration (see Section 2.2). Van Dijk (1983) further states that news discourse can have a conventional schema that stories could use when providing news pieces in either a news article or a news piece in television.

As a last point of discussion for this section, it is important to clarify that Van Dijk (1983) defined news as discourse in his article through the analysis of textual structures of news discourse, thus ignoring "the various contextual conditions and constraints on such textual structures" (p. 28). Such description does not represent a problem for the LWT's news piece analysis since John Oliver's creative team's endeavors for research on a piece use news pieces from news channels, as well as printed articles from newspapers and reports. Thus understanding news discourse in both printed and spoken outlets as similar outlets. In Van Dijk's (1983) words, news discourse "is both a result of and a condition for the cognitive operations of journalists and readers, respectively, in the production, reproduction, or understanding of the news "data" (p. 29). Such 
definition can help represent how the subjectivity and objectivity of facts communicated in news pieces can entail the three characteristics he mentioned in his model, as well as speech acts and the functions they fulfill when providing and communicating news.

\subsection{Comedy news and current social problems}

It has been established that having awareness of how news discourse works, mainly through its characteristics and speech acts fulfilled from the action of providing news, is executed in media outlets. This section will now discuss how and why comedy news has become an outlet for alternative news diets for many people. Burns (2020) comments that Jon Stewart became the pioneer of this new format of comedy shows, becoming the first person to address real-life issues with a comedic twist on The Daily Show. In Burns' words:

[The Daily Show] became significantly more news-driven: this shift was put into sharp focus by their coverage of the 2000 election and politics after $9 / 11$. By 2009, a Time magazine poll showed that Stewart had become the most trusted news anchor on the air [...] The Daily Show was so influential that basically every single comedy news show right now is hosted by its alumni - including John Oliver, Samantha Bee, Hasan Minhaj and Wyatt Cenac. (Burns, 2020)

Burns (2020) comments that Stewart moved on from having interviews with "smalltown politicians or oddballs with the journalistic intensity of reporting on war crimes" (Burns, 2020) to present news pieces and coverages through the use of head-style comedic monologues. The value of this new format for comedy shows has been well received, so much that the study of comedy used in the aforementioned kinds of shows is an important aspect of our current times and our current news consumption. The Daily Show has gone from mocking figures holding political power to influencing groups in society and has also altered the course of important public opinion matters (Brewer et al., 2018) as well as to showcase political figures for the sake of more informed political decisions in 2004 pre-electoral times in the U.S. (Rotfeld, 2005). The Daily Show and, subsequently, Last Week Tonight have left an impact in specific sectors of the public, so much so that comedic journalism has been coined as a term that exemplifies such efforts of providing news and being seen as "legitimate" news sources in the US, for example (Castagner \& Grondin, 2019; Lang, 2019; Michaud Wild, 2019).

Burns further discusses how the implementation of humor works to provide a sense of trust in the people consuming this kind of shows on their media diet. He argues that, with an example of a news show host discussing a political event from the 2020 U.S. elections, that the potency of comedy concerning politics is that it has "the potential to act as a site for radical emancipatory politics, but it can just as easily function in the most ideological fashion and the guise of radicality" (Burns, 2020). He further discusses how comedy, related to its use in comedy news, has the potential to either reaffirm our beliefs about the world or it can help us evidence real-life situations that may or may not have a wider acknowledgment in society or culture.

Comedy can be a magic pill that helps open our eyes to what's really going on. Or it can simply reaffirm the status quo, and help us see contradictions in our world. Or pacify us into contently chuckling about nobody taking away grandpa's keys. Jokes can make us question our world in ourselves or jokes can just affirm what we already know. (Burns, 2020)

He also reaffirms that comedy news serves to inform the public of situations that need the attention of social groups and actors, yet such involvement must happen with nuance and objective criticism: "comedy news shows often work best when [...] they use comedy to critically consider both ends of the political spectrum - even if doing so challenges the audience's assumptions" (Burns, 2020). Such an argument for comedy news to work is what made Jon Stewart's show popular, and he was able to inspire his "alumni" into continuing the tradition of 
comedic journalism (Lang, 2019). John Oliver, being one of his "alumni", often is credited to portray such nuance and objective coverage of news through comedy in his show Last Week Tonight: it "has become known for wide-ranging critiques of powerful people and institutions" (Burns, 2020). Burns (2020) further points out a phenomenon news sources outlets have referred to as the "John Oliver effect" (Konuwa, 2019; Holter, 2016; Michaud Wild, 2019), when the show tackles real-life topics that need public attention and these gain active social relevance, such as U.S. criminal justice reforms, net neutrality regulation, the global tobacco industry, televangelists, and scholarship for women's educational institutions across the U.S., to name a few examples.

As a consequence of the information above, comedy news shows can be understood as outlets that provide nuanced and objective takes on news reports and investigations. Such kind of discourse fulfills the communicative, meaningful, and goal-directed aims news discourse is thought to do so (Van Dijk, 1983), as well as through humorous discourse that is situated within social paradigms that covers aspects of social management, mediational transitions, and functionalization of information transmission (Attardo, 2010). After outlining the theoretical analysis behind comedy news discourse analysis, I will now proceed with the methodology behind such analysis to be carried out.

\section{Methodology}

This section presents the methodological procedure for the analysis of the text chosen and the conceptual framework created for it. The text chosen is the main story that Oliver (2021) presented on his show, regarding how a next pandemic could happen in the future. From this text, Van Dijk's (1983) news discourse structure and Attardo's (2010) and Attardo and Raskin's (1991) canned jokes sequential organization and General Theory of Verbal Humor's (GTVH) jokeforming resources were both used to analyze the news discourse structure and the humorous discourse in the text.

\subsection{News discourse structure (van Dijk, 1983)}

Van Dijk (1983) commented on a model regarding the structuring of news discourse. He comments that news discourse should be seen as a "specific kind of (re)construction of reality according to the norms and values of some society" (p. 28). The perception, construction, and formulation of reality as news events are underlined in factors such as social routines of journalistic (inter)action and fundamental strategies of information processing (Van Dijk, 1983). Another factor he underlies reality as news events is how "the manifestation of a complex process in which knowledge, beliefs, and opinions are matched with existing or incoming information about events, the social contexts of news production, and representations of the reading public" (p. 28). Thus, Van Dijk, states, news production is a form of discourse processing, to that end.

Van Dijk's structure model refers to the use of macrostructures: news discourse organization relies on the importance of these, as macrostructures are represented "by titles or headlines, by initial or final summaries, or by leads" (Van Dijk, 1983: 34). He justifies the importance of macrostructural analysis in mass media, as macrostructures "allow the explicit definition of main topics or themes in messages, even for those cases where these macrostructures are not specifically expressed in surface structures, that is, in titles, leads, or thematical words and sentences" (Van Dijk, 1983: 35). His analysis only applied to written text, yet he commented that news discourse is not only presented in the press but also in television, news articles and/or pieces can be assigned to this kind of structuring framework (Van Dijk, 1983).

Some of the categories in Van Dijk's (1983) structure, as he comments, can be omitted. Omitting certain sections without proper acknowledgment of the background information in a 
news piece can be harmful to the readers/viewers of it. Yet, he states that some of these categories "need not occur explicitly, e.g., because it can be assumed that readers_already have that information or because such information is deemed to be irrelevant" (Van Dijk, 1983, p. 37), and any given understanding of a description of the events told in the news piece can become partially recalled, overgeneralized, or "even biased if readers do not, in fact, have the information" (idem).

The analysis was conducted through Van Dijk's (1983) conventional superstructure of news discourse presented in Figure 1 above. The figure represents how three central aspects of the news piece should be clear to understand the layout of the news piece regarding the headline of the news piece, the event(s) related to the headline, and the comments the news anchor/journalist provides to the events.

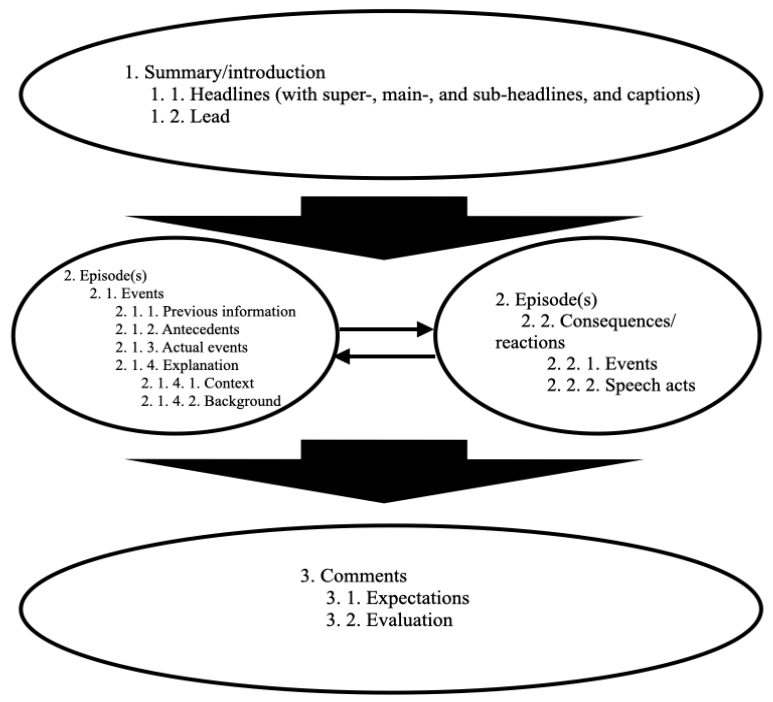

Figure 1. Van Dijk's (1983) conventional superstructure of news discourse

\subsection{Joke texts' framework: Sequential organization of canned jokes, and the general theory of verbal humor}

From Attardo's (2010) extensive body of work regarding humor discourse analysis, I brought the sequential joke-telling organization. The jokes used in the LWT's news piece seem to fall into the denomination of canned jokes, "which has been used before the time of utterance in a form similar to that used by the speaker, such as those which are found in books, collections of jokes, etc.” (pp. 295-296). These kinds of jokes, Attardo (2010) explains, do not depend on contextual factors, meaning the human interactions happening within a conversation are related to information that the hearer may or may not possess, and its strength relies upon how interchangeable within any contexts these jokes can be. It is important to comment here that Attardo (2010) describes that this "acontextuality" jokes possess creates a certain degree of flexibility, as contextual links can be made to the basic structure of a canned joke, thus making it contextually charged yet expected. Attardo (2010) adds to that that "a comedian's monologue, even if it is ultimately composed of a string of jokes, will attempt to connect jokes by their theme or with some sort of narrative connection" (p. 298). Since LWT's news pieces are given in a comedic monologue style, applying Attardo's (2010) canned jokes analysis to the comprehension of jokes used when communicating critical information points in news pieces is relevant to this project. 
2 above.

Canned jokes are laid out in a three-part structure. such structure is laid out in Figure

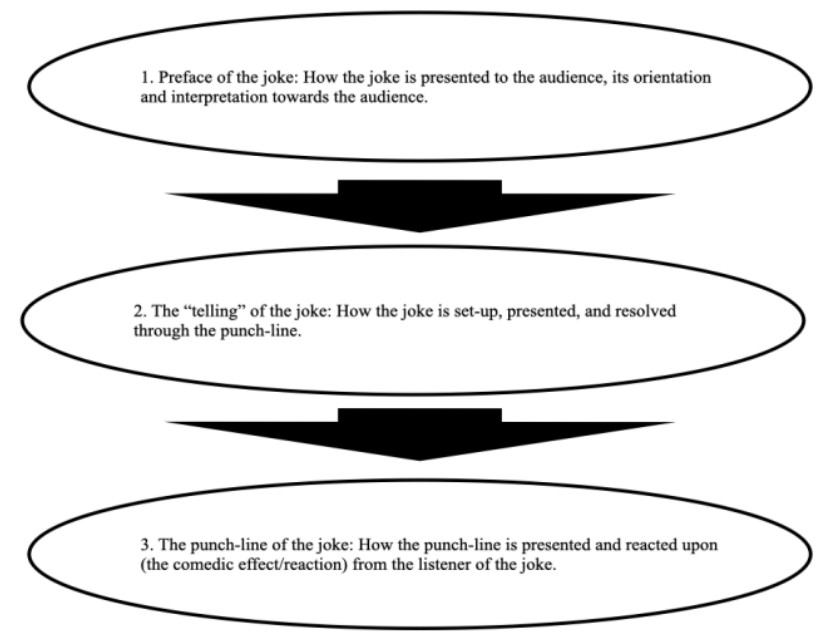

Figure 2. Attardo's (2010) three-part joke analysis structure

The first part, the "preface" of a joke, fulfills the acceptance of the joke-telling to an audience and the orientation of the joke's presentation and interpretation. Secondly, we have the "telling" of the joke, that requires a suspension of disbelief, as Attardo (2010) comments, to accept the text's preface and any kind of incoherence premise that can be set up from the preface of the joke: "if the inconsistencies were challenged, or even acknowledged, the joke would be destroyed because the audience would refuse it on the grounds of its implausibility" (p. 305). The last part of this structure is the punch line of the joke, which is the response provided after hearing the joke text. This will be understood as the comedic reaction to the text joke, since it is the expected answer, but not the only one that can occur.

It is also important for this project also to complement the joke texts framework of analysis with the General Theory of Verbal Humor (henceforth called GTVH, from here onwards). This theory addresses how verbal humor is interpreted and analyzed in the context of discourse analysis. Attardo and Raskin (1991) proposed six joke-informing knowledge resources after the analysis of different parameters and degrees of similarity among jokes examples. Such resources are as follows (Attardo \& Raskin, 1991: 5-17):

(1) script oppositions, in which the second script (or sentence) uttered shows incongruence with the first one;

(2) logical mechanisms, similarly used for reasoning utterances;

(3) situations, which provides more context to a joke or humorous situation;

(4) targets, which normally are the receiver of a joke or humorous statement;

(5) narrative strategies, expectations of text genres such as expository utterances, riddles, a question-and-answer sequence, and so on;

(6) language, which entails word choices, syntactic constructions, text-to-sentence division, among other language options made for the joke uttered.

From these joke-forming knowledge resources, Aliaga-Aguza (2018) comments on her analysis of joke sequences for sitcoms that the application of the GTVH allows for a "selection of jokes indicators and marks that allow to find generalizable patterns to all kinds of humorous texts and analyze these from a linguistic point of view" (p. 136). 
This conceptual framework is then based on Atardo's (2010) sequential organization of canned jokes, Long and Graesser's (1988) descriptors from their taxonomy of jokes, as well as Attardo and Raskin (1991) GTVH's knowledge resources to lay out certain examples of the joke texts related to the news piece. This framework will potentially provide and acknowledge the themes and/or contents a joke text has, the first and second part of Attardo's (2010) canned joke structure, as well as the third part of the structure attributed to the punchline. To that regard, Attardo explains that laughter is attributed with the termination of talk, as well as with signals or attempts to provide "closure of interchanges, but that it also functions as a signal of appreciation of the humorous intent of the speaker, or even serves to "make fun of the speaker" (p. 310). Thus, when a joke text is normally uttered, the expected response is laughter in most cases. This framework will be applied for certain joke texts examples John Oliver uses displayed in Section 3.2, specifically to understand how the preface or premise of these joke texts is laid out (step one), how the set-up is presented and told (step two) and how the punch line is said to generate a response in the receiver/reader of the joke (step three). I will now proceed to discuss the findings of the analyzed LWT's news piece regarding CoVid-19 and possible new pandemics.

\section{Discussion of findings}

This section will address the findings of the analysis made to the LWT's news piece. Both Van Dijk's (1983) superstructure of news discourse analysis as well as the joke texts' conceptual framework put together from Long and Graesser's (1988) taxonomy descriptors, Attardo's (2010) canned joke sequencing, and Attardo and Raskin's (1991) GTVH knowledge resources were implemented in analyzing the news piece and the jokes within it. This section will present figures to provide enough information to the discussion of the overall findings of the news piece structure and specific joke text examples that help convey the analysis made in this paper.

\subsection{News superstructure and news piece elements}

The analysis of the news piece's overall superstructure suggested by Van Dijk (1983) is laid out in Figure 3.

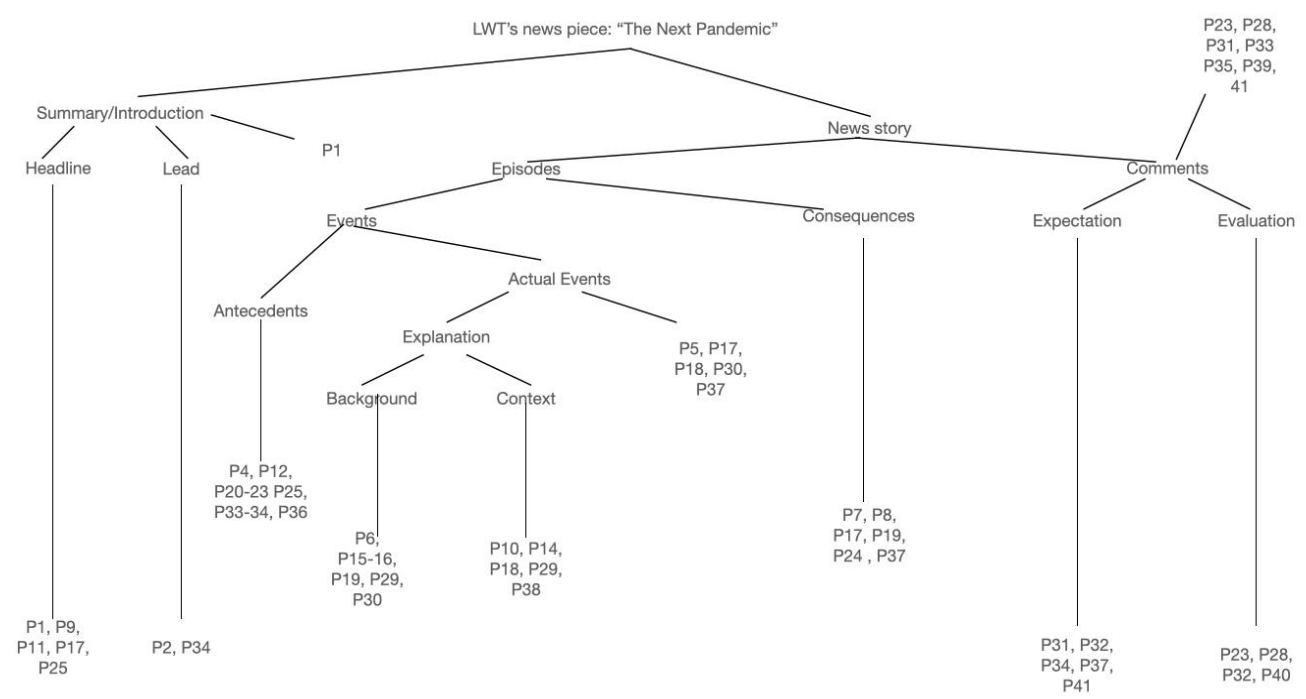

Figure 3. Van Dijk's (1983) conventional superstructure of news discourse applied to LWT's news piece “The Next Pandemic" (Oliver, 2021) 
When analyzing the general aspects of the superstructure, it is evident how the LWT's news piece is heavily charged with pieces of information that work as antecedents, background, and context explanations for the sake of the arguments on the news piece. A concrete example of this is paragraphs 10 to 22, an excerpt of the whole analysis of the news piece shown in Table 1 below, in which John Oliver explains three important points to provide commentary to his headline. These points are how animals are the main agent of virus transmission, the main ones being bats, and how the spreading works in instances of exotic animals being present in human habitats.

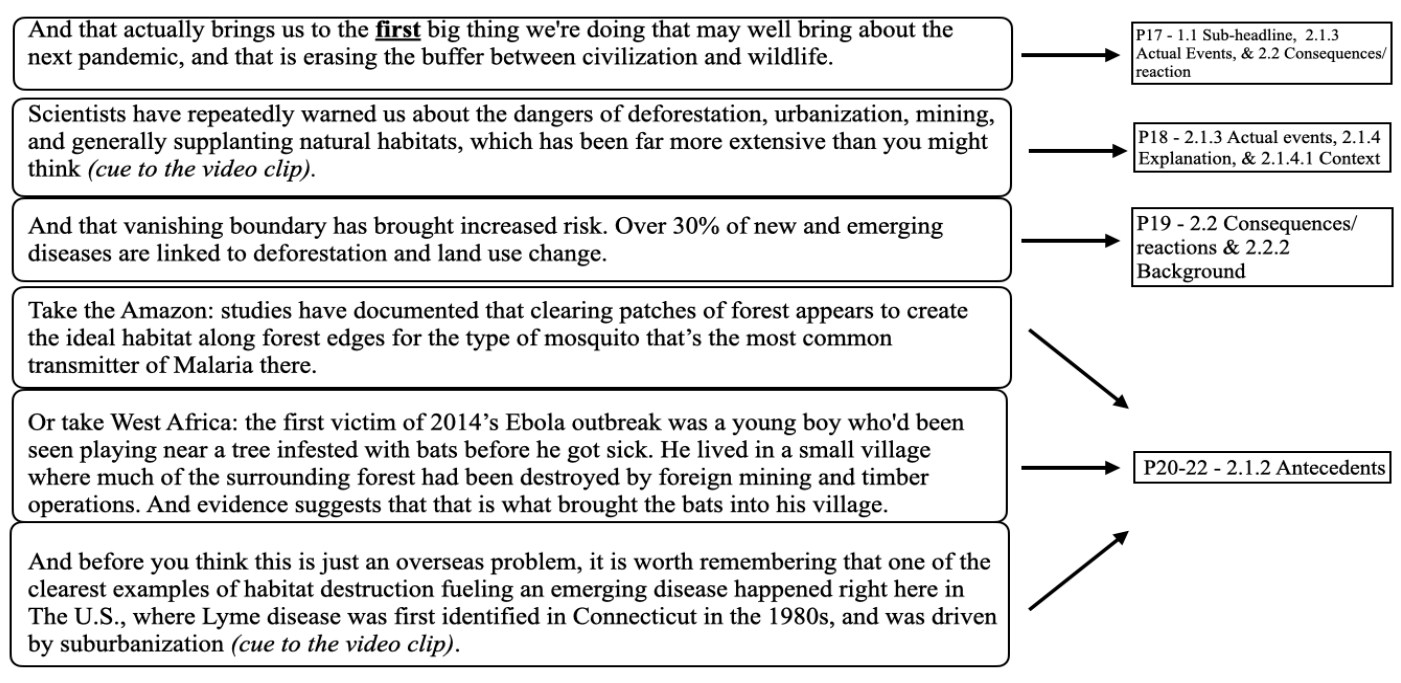

Figure 4.1

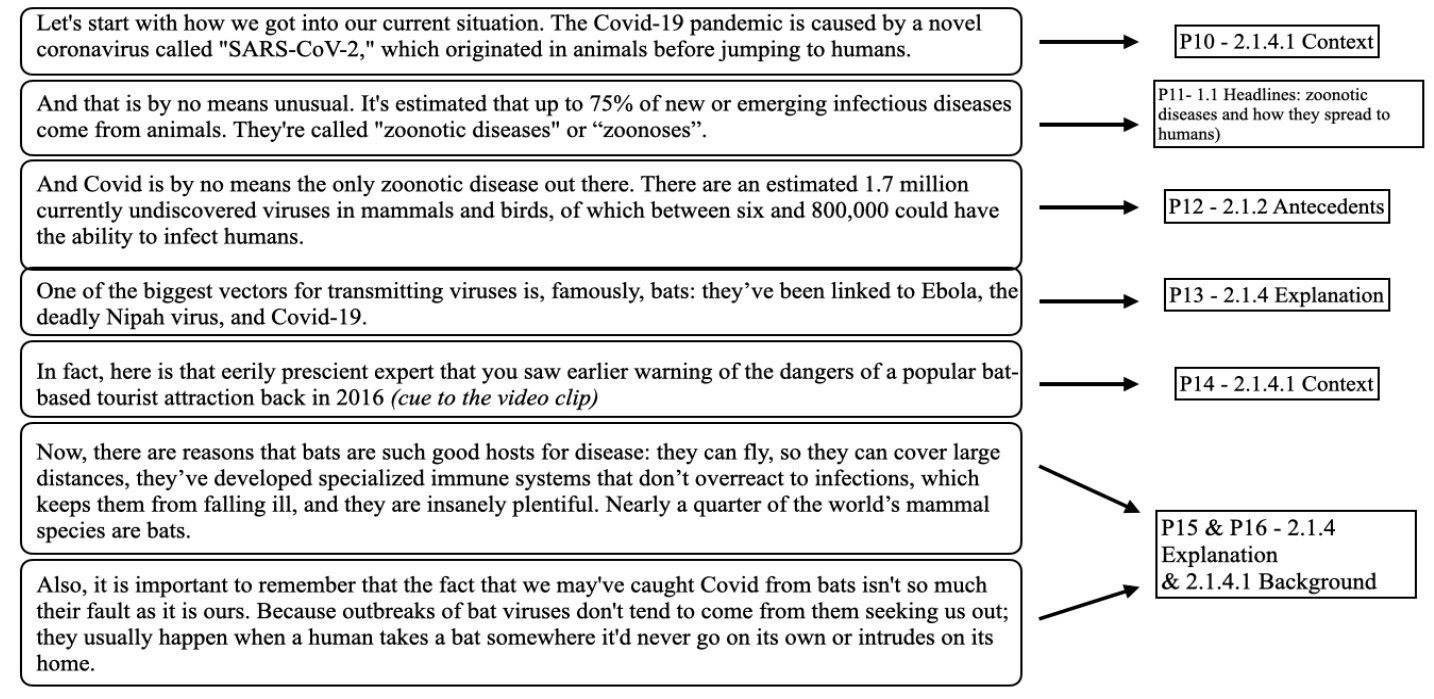

Figure 4.2

Figure 4.1 \& 4.2. Example of LWT's news piece discourse paragraphs 10 to 22: Animals as the main agent of virus transmission, bats, and exotic animals' presence in human habitats

Figure 4.1 and 4.2 above present four instances of explanation, three instances of background information, and two instances of antecedents to help clarify and concrete the point that Oliver wants to communicate. He further expands on these functions in the video with news 
coverage excepts from either U.S. local newscasts or other news networks, such as CNN, Vice, and PBS, to name a few examples. Such video excerpts serve sometimes as both background and context information for the comments made in the news piece or for jokes. What Van Dijk's (1983) superstructure shows in Figure 3 is that other sections of the news piece focus on commenting on the information provided. Such comments fall into the category of expectations for the future of pandemics control and the evaluation of antecedents, background, and context information that reinforce the main events the news piece covers - the Covid-19 pandemic, as well as to address how a possible future pandemic can happen in a bigger and wider scale. They are also reinforced with certain jokes that help ease the harsh reality the information pieces provide. Such comments add up to the headlines of the news piece, referring to how a next pandemic can occur. Through that, the superstructure shows that antecedents, background and context information are set for Oliver to provide comments, expectations, and evaluations. Thus, creating and showing the news piece as a whole text composed of many other sub-functions.

From the analysis above, and connecting Van Dijk's (1983) characteristics of news discourse, the news piece shows how it fulfills the three characteristic functions to make itself worth of being acknowledged as news discourse. The first characteristic, functionality, is fulfilled through the type of social situation (a news anchor giving the news), the characteristic of this report (raising awareness of the current pandemic and measurements of preventing a future one), and the relationship Oliver and the audience has. In spite of Oliver's efforts to down-size the news pieces as "real news", and even joking about how LWT is not a news show, the points that Burns (2020), Holter (2016), Konuwa (2019) and Lang (2019) have made regarding the influence and functionality of the show prove otherwise.

The second characteristic, meaningfulness, is fulfilled through the considerable number of references behind the news piece's events, their contexts and background information, as well as the antecedents for the main theme. Thus, it provides LWT's news piece with the local and global coherence Van Dijk defined (1983: 25-26): the meaning behind news discourse should be either about the discussion of real facts "and to components of facts, such as objects, persons, properties, actions, or events". Consequently, it is proven that the meaningfulness behind the news piece is significant regarding the global coherence (addressing the main theme, the Covid-19 pandemic) and the local coherence (how the different elements of the superstructure are meaningfully related).

The last characteristic, goal-directedness and how social acts can be also understood as speech acts, is also fulfilled. This is seen through the comments, expectations, and evaluations of John Oliver made in relation to and with strong meaningful connections of other elements within the superstructure of the news piece. Such comments fulfill a relevant principle on this characteristic. As a consequence, a speech act can be evidenced as the awareness-raising of a current problem and the antecedents behind it, as well as the background and context of certain other situations linked to the overall theme of the piece. Another speech act that is evidenced as a joke, the overall theme of the news piece, is how John Oliver informs of broad public policies on his shows, either addressing global or domestic politics (for the U.S., at least). That observation is also discussed in joke example \# 5 in Section 3.2, since it is explicitly presented by Oliver himself as a self-deprecating joke.

Overall, the analysis of the news discourse superstructure from Van Dijk (1983) helped analyze in detail the value that LWT's news piece has as news discourse. As such, the fulfillment of the three characteristics Van Dijk (1983) attributed news discourse with provides to the LWT's news piece speech act attributes, thus validating the importance and significance that Burns (2020) discussed on the relevance of comedy news as valuable outlets for information provision to people in recent years. 


\subsection{Canned jokes and GTVH resources analysis}

On this section of the findings, four jokes will be presented and discussed through the conceptual framework acknowledged in Section 2.2.

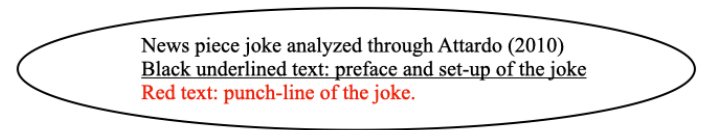

Ex. 1 - (Preface for this joke: video of scientists discussing the erasure of the buffer between wildlife and civilization) $>>$ Three quarters of the terrestrial surface has been changed, a lot of it just to feed one species.

> Oliver: It's true. We've changed three-quarters of the earth's land areas! And while some of that was necessary, we have also changed a lot to build dumb, pointless shit that no one really wants or needs, like paintball courses, or novelty t-shirt shops, or Salt Lake City.

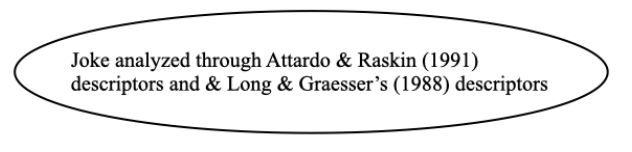

Narrative-strategy-based joke providing a rule of three - marked by the third option being an incongruent one. The punchline of this joke being Salt Lake City.

Non-sense joke, targeted at $\longrightarrow$ commenting the uselessness of a crocodile as a pet.

Figure 5.1

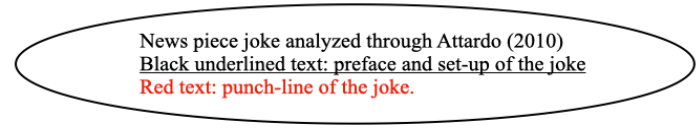

Ex. 3 - The Covid-19 pandemic is caused by a novel coronavirus called "SARS-CoV-2," which originated in animals before jumping to humans. And that is by no means unusual. It's estimated that up to $75 \%$ of new or emerging infectious diseases come from animals. They're called "zoonotic diseases" or "zoonoses", not to be confused with "zoo nose," which, for the record... is a very hurtful thing to call a teenager who's already got enough to deal with.
Ex. 4 - (Preface for this joke: video of a scientist commenting her uncertainty of government-funding for zoonotic disease identification)

> Scientist: It's extremely difficult to get funding for our kind of research. Now, during the pandemic, it has been a little easier. But as soon as the virus crisis is over, our financial worries will return. I'm not very optimistic.

> Oliver: Yeah, that's not great. "I'm not very optimistic" isn't what you want to hear from someone scraping germs out of a bat. That's a woman who literally knows her shit.

Figure 5.2 

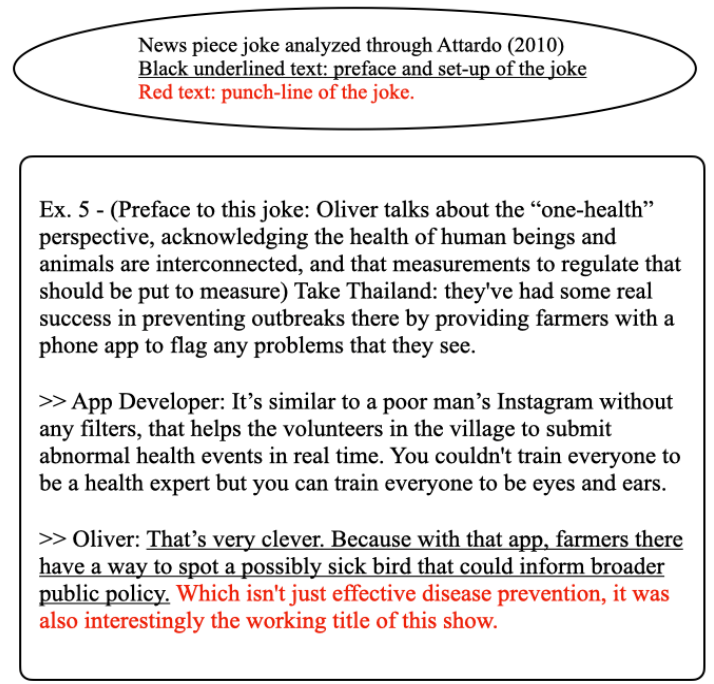

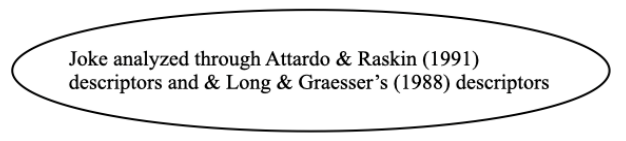

Figure $5 \cdot 3$

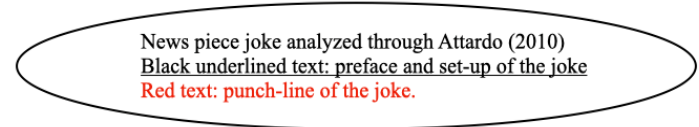

Ex. 6 - (Preface for this joke: video of a reporter examining a wet market with a lot of different wildlife species)

> Reporter: So here in cages right next to each other, we've got adult raccoons next to capybara, which is from South America. Those are from North America. Cages right next to each other. This is the biggest rodent in the world, and on top of here, I think - marmosets on top of the capybara.

> Reporter: What we just saw here is like a biological warfare lab. Any one animal can transmit a pathogen to another, somebody buys it, handles it, takes it home as a pet or eats it. Boom. We have another pandemic.

>> Oliver: Right. When wild animals from different parts of the world are held in close proximity, with weakened immune systems due to stress, pathogens can easily jump from one species to another, and potentially to humans. Which should, at the very least, make you seriously rethink your island in "Animal Crossing." You honestly think it's still a good idea to live in close proximity with a raccoon, an owl, a gorilla, a tiger, a sheep, a koala, an octopus, a

hamster, a penguin, a rhino, and a chicken named Goose, all of whom traveled there from different parts of the world?

That's not an island paradise - it's a disease Chernobyl waiting to happen. Shut that shit down!

\section{Self-deprecating joke, targeted at $\longrightarrow$ John Oliver and said by himself, using demeaning word play.}

Figure 5.4

Figures 5.1-5.4. LWT's example jokes (Oliver, 2021), analyzed through Long and Graesser's

(1988) taxonomy descriptors, Attardo's (2010) canned joke sequencing, and Attardo and Raskin's (1991) GTVH knowledge resources

It is worth acknowledging that the primary social functions these jokes have, based on what Attardo (2010) described, are the primary social function of humor as mediation and defunctionalization. The former makes humorous discourse as a transitional device that permits different other topics or situations to be de-escalated from embarrassing or aggressive outcomes. The difference here is that, on this news piece, such function is used to decode and reduce the harshness of the information given. On the latter, defunctionalization, word plays appear which come into play with a similar function of mediating, yet also fulfilling the purpose of being tonguein-cheek jokes to alleviate the mood of the note, as shown in example 4 of Figure 5.2 above. These primary functions also convey some secondary social functions of providing information and allowing the acceptance of the subject matter and the information presented through jokes, yet 
the texts are mere follow-ups to pieces of information. We will now proceed to comment on the analysis of the joke texts through the conceptual framework.

Some of the LWT's news piece jokes fall into specific descriptors from Long and Graesser's (1988) taxonomy, such as hostile, sexual, social satire, scatological and non-sense jokes that are used to alleviate the tension of the cold data provided on the information points. It was interesting to find a new type that Long and Graesser (1988) did not comment on their taxonomy, and that was self-deprecating humor. This kind of humor is relevant to analyze because Greengross and Miller (2008) interpret self-deprecating humor as a way to make evident the "flaws" of a person or the teller of a joke, through hostile humor directed at her or himself. Such criticism is aimed at aspects such as behaviors, utterances, personality traits, competencies, social status, sexual activeness, and the lack thereof, among others (Greengross \& Miller, 2008). It is worth noting that John Oliver uses hostile criticism as a way to convey jokes, and there is no clearer example of this than in example\# 5 in Figure 5.3 , in which he makes a wordplay with the phrase "a possibly sick bird that could inform broader public policy" and a direct comparison with himself. This kind of humorous discourse also appears at the beginning of the headline addressing zoonotic diseases, in which he points out that the word should not be confused with "zoo nose, which for the record... is a very hurtful thing to call a teenager who's already got enough to deal with" (Oliver, 2021), and automatically presents a photo of himself as a teenager as a resort of more comedic value, setting a graphic punchline shown in Figure 6 below.

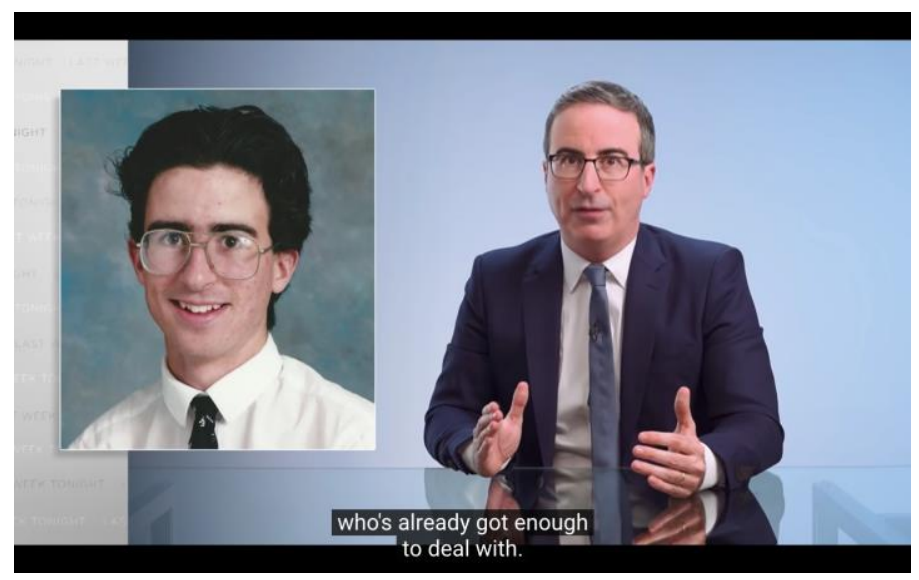

Figure 6. Screenshot of the "self-deprecating" joke (example \#3) (Oliver, 2021)

Thus, this use of self-deprecating humor is implemented as a way to harshly criticize personal traits (Greengross \& Miller, 2008), and from the discussion on the primary and secondary social functions humor is known for (Attardo, 2010), it can be seen that humor is a mechanism that adds value to discourse, in this specific case being news discourse.

Seconded to the analysis above, the jokes also were analyzed contemplating Attardo \& Raskin's (1991) GHTV resources. From these, certain jokes fit into Attardo and Raskin's resources categories, such as narrative strategies: "rule of three" in example 1 and "incongruous comparisons" in example 2 of Figure 5.1, and language-based resources, such as example 5 in Figure 5.3. Attardo and Raskin's (1991) resources helped to identify such joke and humorous text tropes.

The jokes examples in figures 5.1 to 5.4 are then presented here to comment on the style that has characterized LWT's news broadcasting. Oliver uses these jokes, as previously discussed in Section 3.1, to alleviate tension and/or harshness on the pieces of information given to the audience, no matter how incongruous these can end up being. As it was stated by Van Dijk (1983), the analysis dimensions of news discourse are important to consider. That is why, when Van Dijk (1983) referred to rhetorical operations as an example for those, he acknowledged the 
use of different kinds of these in metaphors or ironic statements, for example. It is interesting to acknowledge that three decades later, a new kind of news discourse would appear in comedy news discourse, with the seriousness of journalistic research but also combining jokes to hone the awareness through jokes and humorous discourse. To that degree, Burns (2020) comments that comedic discourse presents a sense of challenge towards one's ideas held by subjective views, this addressed as "egalitarian comedy" by Burns (2020) in which "both the source of the comedy and its target appear divided internally [...] it is the emergence of this internal division that enables us to laugh while also facilitating critique" (Burns, 2020).

\section{Conclusion}

From the analysis of both news discourse and humorous discourse, I was able to find how news discourse presented in the show LWT works through its characteristics and the structure it follows when laying down news pieces. The jokes used in the show serve to fulfill the sense of meditational transitions for the news piece content to be digested by the audience, as well as providing laughter and critique towards objective facts being discussed in it.

The conceptual framework created for this project was then applied to understand and represent the kind of value comedy news discourse has as a speech act, and to see why it works well on people consuming it. Such framework was put together through the use of Van Dijk's (1893) superstructure of news discourse, Attardo's (2010) GTVH's joke-forming resources and Attardo and Raskin (1991) sequences of joke organization, and Long and Graesser's (1988) taxonomy of jokes.

The value that comedy news outlets such as LWT can be attributed to both the fusion of news discourse elements for news coverage and the humorous discourse that allows a better comprehension of the information provided through the deflection and de-escalation of the seriousness of the information provided. This analysis and its results proves the comment Burns (2020) makes about how comedy news discourse and the TV shows true, in the sense that comedy news should be considered as an outlet to spread awareness of situations that need the attention of active participants in society, yet also procuring nuance and objective criticism towards the information given on the journalistic labor this kind of discourse possess.

From the last comment, then, it should be noted that further research or the replication of this kind of framework could be applied to other comedy news outlets to validate and provide different outlets with the same kind of discourse analysis. As such, further analysis of the value of comedy discourse in presenting real-life events or situations could be conducted to acknowledge and treat them with levity through comedy, in contrast to the harsh realities the events represent. After all, "laughter is the best medicine".

\section{Acknowledgements}

I would like to mention the support and advise from my professors Dr. Alejandra Nuñez Asomoza and Dr. Jorge Luis Mendoza Valladares.

This research did not receive any specific grant from funding agencies in the public commercial, or not-for-profit sectors.

The author declares no competing interests. 


\section{References}

Aliaga Aguza, L. Ma (2018). Estudio lingüístico de los indicadores del humor. El caso de la comedia de situación. Normas, 8(1), 129-150. https://doi.org/10.7203/Normas.v8i1.13430

Attardo, S. (2002). Humor and irony in interaction: From mode adoption to failure detection. In L. Anolli, R. Ciceri \& G. Riva (Eds.), Say not to Say: New perspectives on miscommunication (pp.159180). IOS Press.

Attardo, S., \& Raskin, V. (1991). Script theory revis(it)ed: Joke similarity and joke representation model.Humor: International Journal of Humor Research, 4(3-4), 293347. https://doi.org/10.1515/humr.1991.4.3-4.293

Attardo, S. (2010). Chapter 10: Humor in context. In S. Attardo (Ed.), Linguistic theories of humor, Vol. 1 (pp. 293-331). Walter de Gruyter.

Brewer, P. R., Young, D. G., Lambe, J. L., Hoffman, L. H., \& Collier, J. (2018). "Seize your moment, my lovely trolls": News, satire, and public opinion about net neutrality. International Journal of Communication, 12, 23.

Burns, M. (2020, May 22) COMEDY NEWS: Is it Deep or Dumb? [Video file]. YouTube. https://www.youtube.com/watch?v=QumeDEv3DyM.

Castagner, M. O., \& Grondin, D. (2019). From irritated hostages to silly citizens. In M. R. Meier (Ed.), The joke is on us: Political comedy in (late) neoliberal times (pp. 133-158). Lexington Books.

Holter, L. (2016, Feb 8). 5 Times John Oliver Changed the World (Kinda). Bustle News. https://www.bustle.com/articles/140358-5-times-john-oliver-made-a-real-impact-provedthat-late-night-shows-arent-all-fun.

Greengross, G., \& Miller, G. F. (2008). Dissing oneself versus dissing rivals: Effects of status, personality, and sex on the short-term and long-term attractiveness of self-deprecating and otherdeprecating humor. Evolutionary Psychology, 6(3). 393-408. https://doi.org/10.1177/147470490800600303

Konuwa, A. (2019, April 1). HBO's John Oliver Encourages Chants for Workers' Compensation at WrestleMania 35 In WWE Hit Piece. Forbes. https://www.forbes.com/sites/alfredkonuwa/2019/04/01/hbos-john-oliver-encourageschants-for-workers-compensation-at-wrestlemania-35-in-wwe-hit-piece/?sh=3e23e86143be.

Lang, A (2019, March 8). Are political comedians reliable sources of news? The University Daily Kansan. https://www.kansan.com/news/are-political-comedians-reliable-sources-ofnews/article 866492d4-4159-11e9-bcfo-b73ff73coe7d.html.

Michaud Wild, N. (2019). “The mittens of disapproval are on": John Oliver's Last Week Tonight as neoliberal critique. Communication, Culture \& Critique, 12(3), 340-358. https://doi.org/10.1093/ccc/tczO21

Long, D. L., \& Graesser, A. C. (1988). Wit and humor in discourse processing. Discourse processes, 11(1), 35-60.

Oliver, J. (2021, February 15). The Next Pandemic: Last Week Tonight with John Oliver (HBO) [Video file]. YouTube. https://www.youtube.com/watch?v=v-U3K1sw9U.

Rotfeld, H. J. (2005). And a comedian shall show journalists the way. Journal of Consumer Marketing, 22(3), 119-120.

Van Dijk, T. A. (1983). Discourse analysis: Its development and application to the structure of news. Journal of communication, 33(2), 20-43. 